\title{
Antithrombotic effect of Lonomia obliqua caterpillar bristle extract on experimental venous thrombosis
}

\author{
B.C. Prezoto ${ }^{1}$, \\ F.H.A. Maffei ${ }^{3}$, \\ L. Mattar ${ }^{3}$, \\ A.M. Chudzinski-Tavassi ${ }^{2}$ \\ and P.R. Curi ${ }^{3}$
}

\author{
Laboratórios de ${ }^{1}$ Farmacologia, and ${ }^{2}$ Bioquímica e Biofísica, Instituto Butantan, \\ São Paulo, SP, Brasil \\ ${ }^{3}$ Departamento de Cirurgia e Ortopedia, Faculdade de Medicina de Botucatu, \\ Universidade Estadual Paulista, Botucatu, SP, Brasil
}

\section{Correspondence \\ B.C. Prezoto \\ Laboratório de Farmacologia \\ Instituto Butantan \\ Av. Vital Brasil, 1500 \\ 05503-900 São Paulo, SP \\ Brasil \\ Fax: +55-11-3726-1024 \\ E-mail: benecp@ hotmail.com \\ Part of the results were presented at the XVII Congress of the \\ International Society for \\ Thrombosis and Haemostasis, \\ Washington, DC, USA, August 14-21, 1999.}

Research supported by CAPES and FAPESP. B.C. Prezoto is supported by CNPq (No. 143583/96-4).

Received July 6, 2001

Accepted March 19, 2002

\section{Abstract}

The venom of Lonomia obliqua caterpillar may induce a hemorrhagic syndrome in humans, and blood incoagulability by afibrinogenemia when intravenously injected in laboratory animals. The possible antithrombotic and thrombolytic activities of L. obliqua caterpillar bristle extract (LOCBE) were evaluated in this study. The minimal intravenous dose of the extract necessary to induce afibrinogenemia and anticoagulation was 3.0 and $10.0 \mu \mathrm{g}$ protein $/ \mathrm{kg}$ body weight for rabbits and rats, respectively. In rabbits, this dose induced total blood incoagulability for at least $10 \mathrm{~h}$ and did not reduce the weight of preformed venous thrombi, in contrast to streptokinase $(30,000 \mathrm{IU} /$ $\mathrm{kg}$ ). In rats, pretreatment with 5.0 and $10.0 \mu \mathrm{g} / \mathrm{kg}$ LOCBE prevented the formation of thrombi induced by venous stasis or by injury to the venous endothelium. The dose of $5.0 \mu \mathrm{g} / \mathrm{kg}$ LOCBE did not modify blood coagulation assay parameters but increased bleeding time and decreased plasma factor XIII concentration. When the extract was administered to rats at the dose of $10.0 \mu \mathrm{g} / \mathrm{kg}$, the blood was totally incoagulable for $6 \mathrm{~h}$. These data show that LOCBE was effective in preventing experimental venous thrombosis in rats, justifying further studies using purified fractions of the extract to clarify the mechanisms of this effect.

\section{Introduction}

Many natural substances derived from invertebrates have toxic effects on the blood coagulation and fibrinolytic systems of mammals (1). Some of these substances have been well characterized and studied as alternative drugs in the treatment of pathological processes that affect the hemostatic system. Hirudin (2) and tick anticoagulant peptide (3) are examples of substances which have been studied both experimentally and clini-
Key words

- Thrombosis

- Fibrinolysis

- Anticoagulant

- Venom

- Lonomia obliqua caterpillar cally as possible antithrombotic drugs because of their anticoagulant activity in vivo.

Cases of acquired hemorrhagic diathesis in humans due to accidental contact with Lonomia caterpillar bristles ( $L$. achelous and $L$. obliqua) have been reported in South America. Symptoms of acute envenoming by these two caterpillars consist of local pain, ecchymosis, headache, acute renal failure and hemorrhagic episodes. These episodes, which sometimes can be fatal, affect mucous membranes, lungs, intraperitoneal cavity and the central 
nervous system or medullary canal. L. obliqua (Walker) is found mainly in the southern states of Brazil and L. achelous in Venezuela.

Arocha-Piñango et al. $(4,5)$ have published several studies on aspects of $L$. achelous envenomation, common laboratory findings in envenomed patients $(6,7)$, and on the effects of the venom and fractions derived from the venom on coagulation and fibrinolysis (8-12).

L. obliqua caterpillar bristle extract (LOCBE) induces in vitro calcium-dependent procoagulant activity both in human and rat plasma (13), probably due to the activation of prothrombin and factor $\mathrm{X}$, with no effects on platelets (14). In vivo, it causes blood incoagulability in laboratory animals $(15,16)$. Recently, an L. obliqua prothrombin-activator serine-protease was isolated from LOCBE and characterized in our laboratory (16).

Since LOCBE induces blood incoagulability, the aim of the present study was to investigate its effects in preventing thrombus formation in the vena cava and jugular vein of rats, and a possible lytic action on preformed thrombus in the jugular vein of rabbits, as an initial screening for further studies.

\section{Material and Methods}

\section{Animals}

Male Wistar rats (280-350 g) and male New Zealand rabbits (3.0-4.2 kg) were bred at Instituto Butantan, São Paulo, SP, Brazil. The animals had free access to water and food and were on a 12-h light-dark cycle. Procedures involving animals and their care were conducted in accordance with the Guidelines for the Use of Animals in Biochemical Research (17).

\section{Drugs}

The drugs used were streptokinase (Carlo
Erba, São Paulo, SP, Brazil), sodium pentobarbital (a gift from Abbott do Brasil, São Paulo, SP, Brazil), sodium heparin (Liquemine, Roche Pharmaceuticals, São Paulo, SP, Brazil), bovine thrombin (Hoffman-La Roche, Basel, Switzerland), thromboplastin (Baxter Diagnostic Inc., Deerfield, IL, USA), sodium iodoacetate (Aldrich Chemical Company, Inc., Milwaukee, WI, USA), factor XIII reagents (Diagnostica Stago, Asnières, France), urea and rabbit brain cephalin (Sigma, St. Louis, MO, USA), and human fibrinogen (Chromogenix, Mölndal, Sweden).

\section{Preparation of the L. obliqua caterpillar bristle extract}

L. obliqua were collected in rural areas of Rio Grande do Sul and Santa Catarina and maintained in the Laboratory of Entomology of Instituto Butantan. Preparation of a crude LOCBE has been standardized (15). Fifteen caterpillars were anesthetized under a $\mathrm{CO}_{2}$ atmosphere, the bristles were cut off with scissors at their insertion in the tegument and suspended $(10 \%, w / v)$ in cold phosphatebuffered saline, $\mathrm{pH}$ 7.4. This suspension was homogenated and centrifuged at $2100 \mathrm{~g}$ for $10 \mathrm{~min}$ at $4^{\circ} \mathrm{C}$. The supernatant was collected and its protein content was determined using a modification of the Lowry method (18). Supernatant aliquots were stored at $-70^{\circ} \mathrm{C}$ and the same batch was used in all experiments.

\section{Antithrombotic activity of LOCBE injected into the vena cava and jugular vein of rats}

Determination of LOCBE doses for intravenous (iv) administration in rats. Previous studies have found that the minimal dose of LOCBE needed to incoagulate the blood (MDIB) after intradermal injection in rats was $140 \mu \mathrm{g} / \mathrm{kg}$ (15). For the determination of MDIB for $i v$ administration, the rats were anesthetized with sodium pentobarbital (60 
$\mathrm{mg} / \mathrm{kg}$, intraperitoneally, ip). LOCBE infusions ( $1 \mathrm{ml}$ ) were administered over a period of $30 \mathrm{~min}$ into the cannulated right jugular vein at doses that varied from 2.5 to 140.0 $\mu \mathrm{g} / \mathrm{kg}$ for each group of 4 animals. Thirty minutes after the end of the infusion, $1 \mathrm{ml}$ of blood was collected from the carotid artery with a siliconized needle for the measurement of whole blood clotting time (WBCT). WBCT was determined by measuring the clotting time of $1 \mathrm{ml}$ of venous blood in a glass test tube at $37^{\circ} \mathrm{C}(19)$. The MDIB obtained was $10.0 \mu \mathrm{g} / \mathrm{kg}$. The duration of the anticoagulant effect of LOCBE was determined in these experiments using doses corresponding to $0.5,1$ and $2 \mathrm{MDIB}$ and by measuring WBCT at 0.5, 2, 5, 10, and $24 \mathrm{~h}$ after the end of infusion. Blood samples were also collected from control animals treated with saline. The rats were randomly allocated to groups of 4 animals each.

\section{Prevention of thrombus formation in rats}

Prevention of thrombus formation by treatment with LOCBE was tested in two different models of experimental thrombosis: one caused mainly by stasis in the vena cava, and the other by endothelium injury in the jugular vein. For both experiments, rats were anesthetized with sodium pentobarbital $(60 \mathrm{mg} / \mathrm{kg}$, ip) and randomly allocated to one of the following groups of 8 animals each: control (saline), $300 \mathrm{IU} / \mathrm{kg}$ heparin, and $2.5,5.0$ and $10.0 \mu \mathrm{g} / \mathrm{kg}$ LOCBE. Drugs $(1 \mathrm{ml} / 30 \mathrm{~min}$ ) were infused into the left jugular vein $1 \mathrm{~h}$ before thrombus induction.

The technique described by Reyers et al. (20) was used for stasis-induced thrombus formation in the vena cava. Briefly, the abdomen was opened with a midline incision, the vena cava isolated, and all branches between the left renal vein and iliac veins were tied. The vena cava was tied just caudally to the left renal vein and the incision closed. Four hours later, the animals were re-anesthetized, the abdominal incision was reopened and the vena cava segment removed. When the thrombus was present, it was removed from the segment, blotted on filter paper, and weighed both immediately (wet weight) and after drying at $37^{\circ} \mathrm{C}$ for $24 \mathrm{~h}$ (dry weight).

The technique described by Maffei et al. (21), with modifications in the solution used and in the way of injection, was used for injury-induced thrombus formation in the jugular vein. Briefly, the right jugular vein was exposed through a midline incision in the neck. The vein was cleared and a segment was isolated with two cotton thread loops placed $1 \mathrm{~cm}$ apart. The segment had the blood removed through an internal jugular vein tributary and was then filled with $50 \%$ glucose. Ten minutes later, the blood flow was re-established by removal of the loops, the internal jugular vein was tied, and the incision closed. Three hours later, the animals were re-anesthetized, the vein segment was removed, and when present, the thrombus was collected and weighed as described previously.

Blood samples ( $2 \mathrm{ml})$ were collected from the carotid arteries before drug infusion, thrombus induction, and vein removal. Prothrombin time (PT) and activated partial thromboplastin time (APTT) were measured according to standardized techniques described by Denson (19), with standardized reagents. To measure thrombin time (TT), $100 \mu \mathrm{l}$ of thrombin $(6 \mathrm{IU} / \mathrm{ml})$ was added to $200 \mu \mathrm{l}$ of plasma and the clotting time recorded at $37^{\circ} \mathrm{C}(22)$. Fibrinogen was estimated by the method of Ratnoff and Menzie (23). Bleeding time (BT) was also measured by making a small incision ( $3 \mathrm{~mm}$ in length, $2 \mathrm{~mm}$ in depth) $9 \mathrm{~cm}$ from the tail end. The tail was immersed in $0.9 \%$ saline at $37^{\circ} \mathrm{C}$, and the time of bleeding cessation was recorded (24).

\section{Effect of LOCBE on whole blood lysis time and plasma factor XIII activity}

To study the in vivo effect of LOCBE on 
plasma factor XIII activity, LOCBE was infused $i v$ at the dose of $5.0 \mu \mathrm{g} / \mathrm{kg}$, and WBCT, whole blood lysis time (WBLT) and plasma factor XIII activity were measured. Blood was collected from 8 rats 5 min before (control) and $30 \mathrm{~min}$ after LOCBE infusion. WBCT was determined by measuring the clotting time of $1 \mathrm{ml}$ of venous blood in a glass test tube at $37^{\circ} \mathrm{C}(19)$, and WBLT by measuring the time needed for clot lysis. Factor XIII zymogen concentration in plasma samples was determined using the sodium iodoacetate tolerance test (25). Briefly, plasma clots were formed by recalcification of plasma samples $\left(100 \mu \mathrm{l}\right.$ of $50 \mathrm{mM} \mathrm{CaCl}_{2}$ $+200 \mu \mathrm{l}$ of plasma) in the presence of $100 \mu \mathrm{l}$ of sodium iodoacetate at different concentrations (from 5 to $35 \mathrm{mM}$ ). After incubation for $30 \mathrm{~min}$ at $37^{\circ} \mathrm{C}, 3 \mathrm{ml}$ of $5 \mathrm{M}$ urea was added and time for clot dissolution was measured. The control plasma was diluted to the same fibrinogen concentration as the tested plasma.

\section{Evaluation of LOCBE thrombolytic activity on preformed thrombus in rabbits}

The MDIB for $i v$ administration in nonanesthetized rabbits, determined by the same procedure as used in rats, was $3.0 \mu \mathrm{g} / \mathrm{kg}$. Drugs were infused through the marginal vein of one ear, and blood samples were collected from the marginal vein of the contralateral ear.

Thrombi were induced using the technique of Rollo et al. (26). Briefly, rabbits were anesthetized by $i v$ injection of sodium pentobarbital $(30 \mathrm{mg} / \mathrm{kg})$. A 5 -cm segment of the right jugular vein (above the junction of the internal and external jugular veins) was dissected free of surrounding tissue and all side branches were tied. Three semiocclusive cotton ligatures $1.2,1.0$ and 0.8 $\mathrm{mm}$ in diameter were placed around the jugular vein $2 \mathrm{~mm}$ apart, with the help of three different needles. The stenosis with the smaller diameter was placed closer to the heart, and a funnel-like structure was formed. Two cotton thread loops were placed above the funnel-like structure in order to isolate a 2-cm long segment. Blood in this segment (about $0.5 \mathrm{ml}$ ) was collected from a small side branch into a syringe containing $30 \mathrm{U}$ of thrombin, and $50 \mu \mathrm{l}$ of this mixture was reinjected through this branch into the vein. After injection, the side branch was tied and the blood allowed to clot. Ten minutes later, both vessel loops were removed and blood flow was re-established. The formed thrombus was trapped in the funnel but did not block the blood flow, remaining trapped until the beginning of drug infusion.

Different doses of LOCBE (1.5, 3.0 and $4.5 \mu \mathrm{g} / \mathrm{kg}$ ) were infused for evaluation of its possible thrombolytic activity. The doses were infused through the marginal vein (30 $\mathrm{ml} / 2 \mathrm{~h}$ ) starting $30 \mathrm{~min}$ after loop removal. The rabbits in one control group received only vehicle (isotonic saline), and those in the other group received streptokinase $(30,000 \mathrm{IU} / \mathrm{kg})$. The rabbits were randomly allocated to these treatment groups of 8 animals each.

Three hours after drug infusion, the animals were re-anesthetized and the venous segment was removed. The thrombus was removed from the segment, blotted on filter paper and weighed both immediately (wet weight) and after drying for $24 \mathrm{~h}$ at $37^{\circ} \mathrm{C}$ (dry weight). Blood samples $(3.0 \mathrm{ml}+3.8 \%$ sodium citrate $1: 10(\mathrm{v} / \mathrm{v}))$ were collected from the marginal vein of the contralateral ear 15 min before thrombus induction and before thrombus evaluation. These samples were centrifuged for $10 \mathrm{~min}$ at $2000 \mathrm{~g}$ to obtain plasma and kept refrigerated until analysis on the same day. The following tests were performed: PT, APTT, TT, fibrinogen concentration, and fibrinolytic activity of the euglobulin fraction.

\section{Coagulation and fibrinolysis assays}

PT, APTT, TT and fibrinogen concentra- 
tion were measured as described above. For determination of fibrinolytic activity, the euglobulin fraction was prepared with $200 \mu \mathrm{l}$ of plasma diluted in $1.8 \mathrm{ml}$ of cold water, precipitated with $150 \mu \mathrm{l}$ of $0.25 \%$ acetic acid (27) and resuspended in $200 \mu \mathrm{l}$ of $100 \mu \mathrm{M}$ $0.1 \%$ Tris Tween buffer, $\mathrm{pH} 7.4$ (28). The fibrinolytic activity of the euglobulin fraction was measured using the fibrin-agarose plate method (29). Fibrin-agarose plates were prepared with a $1 / 1$ mixture of $2.0 \mathrm{mg} / \mathrm{ml}$ of human fibrinogen (Chromogenix) and 2.0\% agarose (Sigma) diluted in $100 \mathrm{mM}$ sodium pentobarbital buffer, $\mathrm{pH} 7.75$, containing $1.66 \mathrm{M} \mathrm{CaCl}_{2}, 0.68 \mathrm{mM} \mathrm{MgCl} 2$, and 93.3 $\mathrm{mM} \mathrm{NaCl}$. Six milliliters of this mixture was placed on plastic dishes $9 \mathrm{~cm}$ in diameter and clotted with 4 NIH U of bovine thrombin. Three to six samples of $30 \mu \mathrm{l}$ of euglobulin fractions were applied to each plate. After 18 $\mathrm{h}$ at $37^{\circ} \mathrm{C}$, lysis areas $\left(\mathrm{mm}^{2}\right)$ were calculated as the product of two perpendicular diameters. The results are reported as means $\pm \mathrm{SD}$ for $\mathrm{N}=8$ in each experimental group.

\section{Statistical analysis}

The results are reported as means $\pm \mathrm{SD}$. The results of coagulation tests (TT, APTT, PT, BT) and fibrinolytic activity (lysis area on fibrin-agarose plates) before and after treatment were analyzed by the Student paired $t$-test. Analysis of variance (ANOVA) for completely randomized groups was used for the evaluation of differences between groups. The incidence of thrombi in the drug-treated groups was compared to the control group (isotonic saline) by the Fisher exact test. Factor XIII activity was compared before and after LOCBE treatment by the non-parametric Wilcoxon test. Differences between groups were compared by the Kruskal-Wallis test (30). The differences were considered significant when $\mathrm{P}<0.05$.

\section{Results}

\section{Determination of the minimum doses of LOCBE needed to incoagulate blood}

The MDIB by $i v$ LOCBE infusion in rats was $10.0 \mu \mathrm{g} / \mathrm{kg}$. This dose induced blood incoagulability for at least $10 \mathrm{~h}$ with return of the WBCT to normal values before $24 \mathrm{~h}$.

\section{Evaluation of LOCBE antithrombotic activity in vena cava and jugular vein of rats}

Vena cava. All animals of the control group treated with saline $(\mathrm{N}=8)$ and of the LOCBE group treated with $2.5 \mu \mathrm{g} / \mathrm{kg}$ $(\mathrm{N}=8)$ presented thrombi. The frequency in each group is presented in Table 1 . LOCBE at the dose of $5.0 \mu \mathrm{g} / \mathrm{kg}$ prevented

\begin{tabular}{|c|c|c|c|c|c|c|}
\hline \multirow[t]{2}{*}{ Groups } & \multicolumn{3}{|c|}{ Vena cava } & \multicolumn{3}{|c|}{ J ugular vein } \\
\hline & $T / n$ & WW & DW & $T / n$ & WW & DW \\
\hline Saline & $8 / 8$ & $19.75 \pm 3.37$ & $5.91 \pm 0.92$ & $8 / 8$ & $20.88 \pm 2.92$ & $8.50 \pm 1.34$ \\
\hline $\begin{array}{l}\text { Heparin } \\
\text { LOCBE }\end{array}$ & \multicolumn{5}{|c|}{ LOCBE $(\mu \mathrm{g} / \mathrm{kg})$} & $3.94 \pm 1.02$ \\
\hline 2.5 & $8 / 8$ & $20.00 \pm 3.42$ & $6.02 \pm 1.52$ & $8 / 8$ & $21.05 \pm 2.67$ & $8.75 \pm 1.56$ \\
\hline 5.0 & $1 / 8^{*}$ & 11.00 & 4.58 & $2 / 8^{*}$ & $9.60 \pm 4.23$ & $3.81 \pm 1.56$ \\
\hline 10.0 & $0 / 8 *$ & 0 & 0 & $0 / 8^{*}$ & 0 & 0 \\
\hline
\end{tabular}

Values are reported as $\mathrm{mg}$ (means $\pm \mathrm{SD}$ ). $\mathrm{N}=8$ animals in each group. WW, wet weight; DW, dry weight; $T / n$, number of animals with thrombus.

$* \mathrm{P}<0.05$ for each treatment group compared to control (paired t-test). 
thrombus formation in 7 of the 8 animals, without significant differences in coagulation assay values when compared with preinfusion values. LOCBE at the dose of 10.0 $\mu \mathrm{g} / \mathrm{kg}$ inhibited thrombus formation in all treated animals and induced total incoagulability (Table 2).

The lower doses of LOCBE (2.5 and 5.0 $\mu \mathrm{g} / \mathrm{kg}$ ) did not significantly change TT, PT, or APTT when compared with pre-infusion values. However, $5.0 \mu \mathrm{g} / \mathrm{kg}$ LOCBE increased BT from $114.25 \pm 1.22$ to $141.00 \pm$ $2.60 \mathrm{~s}$ at $30 \mathrm{~min}$ and to $139.75 \pm 1.53 \mathrm{~s}$ at the end of the experiment $(\mathrm{P}<0.05)$. The highest dose of LOCBE $(10.0 \mu \mathrm{g} / \mathrm{kg})$ increased BT from $109.62 \pm 1.96$ to $261.37 \pm 10.37 \mathrm{~s}, 30$ min after the end of the infusion, and to $257.50 \pm 8.72 \mathrm{~s}$ at the end of the experiment (Table 2).

Heparin $(300 \mathrm{IU} / \mathrm{kg}$ ) prevented thrombus formation in 6 of the 8 treated animals, and caused a significant increase in TT, PT, APTT and BT assays in all animals (Table 2). Significant reduction of thrombus mean weight was observed in the two other animals (Table $1)$.

Thirty minutes after infusion, LOCBE reduced the plasma fibrinogen concentrations to $75 \%$ of the mean control value at 5.0 $\mu \mathrm{g} / \mathrm{kg}$ and to undetectable values at $10.0 \mu \mathrm{g} /$ $\mathrm{kg}(\mathrm{N}=8)($ Table 3$)$.

Jugular vein. The injection of $50 \%$ glucose solution into the jugular vein segment of rats led to the development of an occlusive thrombus in $100 \%$ of the animals treated with saline (control group) and with $2.5 \mu \mathrm{g} /$ $\mathrm{kg}$ LOCBE. Heparin (300 IU/kg) and $5.0 \mu \mathrm{g} /$ $\operatorname{kg} \operatorname{LOCBE}(\mathrm{N}=8$ for each treatment group) prevented thrombus formation in 5 and 6 of the 8 treated animals, respectively. Thrombus mean weight in the remaining animals was significantly reduced (Table 1 ).

The effects of $\operatorname{LOCBE}(2.5,5.0$ and 10.0 $\mu \mathrm{g} / \mathrm{kg}$ ) and heparin (300 IU/kg) treatments

Table 2. Effects of heparin and Lonomia obliqua caterpillar bristle extract (LOCBE) infusion on the coagulation parameters of rats.

\begin{tabular}{|c|c|c|c|c|}
\hline \multirow[t]{2}{*}{ Compound } & \multicolumn{4}{|c|}{ Assays } \\
\hline & $\pi$ & PT & APTT & BT \\
\hline \multicolumn{5}{|c|}{ Heparin (300 IU/kg) } \\
\hline$-5 \min$ & $16.62 \pm 0.50$ & $13.50 \pm 0.68$ & $19.25 \pm 0.82$ & $103.62 \pm 2.84$ \\
\hline$+30 \min$ & $24.25 \pm 0.96 *$ & $25.12 \pm 1.37 *$ & $37.87 \pm 1.01 *$ & $132.37 \pm 1.52^{*}$ \\
\hline$+240 \mathrm{~min}$ & $25.50 \pm 0.68^{*}$ & $23.75 \pm 1.16^{*}$ & $41.62 \pm 1.19 *$ & $129.75 \pm 3.60^{*}$ \\
\hline \multicolumn{5}{|c|}{ LOCBE $(2.5 \mu \mathrm{g} / \mathrm{kg})$} \\
\hline$-5 \min$ & $17.25 \pm 0.88$ & $13.12 \pm 0.58$ & $17.87 \pm 1.03$ & $115.00 \pm 3.51$ \\
\hline +30 min & $15.87 \pm 0.87$ & $12.25 \pm 0.37$ & $17.86 \pm 0.91$ & $112.87 \pm 2.12$ \\
\hline$+240 \min$ & $18.25 \pm 0.75$ & $13.50 \pm 0.57$ & $17.62 \pm 0.80$ & $108.62 \pm 2.99$ \\
\hline \multicolumn{5}{|c|}{ LOCBE $(5.0$ g/kg) } \\
\hline$-5 \min$ & $18.25 \pm 0.75$ & $12.75 \pm 0.45$ & $19.25 \pm 0.88$ & $114.25 \pm 1.22$ \\
\hline$+30 \mathrm{~min}$ & $17.62 \pm 0.60$ & $12.50 \pm 0.42$ & $20.00 \pm 0.65$ & $141.00 \pm 2.60^{*}$ \\
\hline$+240 \mathrm{~min}$ & $17.75 \pm 0.65$ & $14.00 \pm 0.46$ & $21.00 \pm 1.13$ & $139.75 \pm 1.53^{*}$ \\
\hline \multicolumn{5}{|c|}{ LOCBE $(10.0$ g./kg) } \\
\hline$-5 \mathrm{~min}$ & $18.37 \pm 0.60$ & $13.00 \pm 0.40$ & $19.00 \pm 0.71$ & $109.62 \pm 1.96$ \\
\hline$+30 \mathrm{~min}$ & Inc* & Inc* & Inc* & $261.37 \pm 10.37^{*}$ \\
\hline$+240 \min$ & Inc* & Inc* & Inc* & $257.50 \pm 8.72^{*}$ \\
\hline
\end{tabular}


on coagulation assays, plasma fibrinogen concentration, and BT were similar to those found in the vena cava experiments.

\section{Effects of $5.0 \mu \mathrm{g} / \mathrm{kg}$ LOCBE on whole blood lysis time and plasma factor XIII}

WBLT of samples collected $30 \mathrm{~min}$ after LOCBE infusion $(5.0 \mu \mathrm{g} / \mathrm{kg})$ decreased significantly (from $>24$ to $<2 \mathrm{~h}$ ) in all animals $(\mathrm{N}=8)$. Clots formed in plasma in the presence of all sodium iodoacetate concentrations were dissolved in $5 \mathrm{M}$ urea within less than $90 \mathrm{~min}$. Control plasma clots were insoluble after $6 \mathrm{~h}(\mathrm{P}<0.001)$ (Wilcoxon test).

\section{Determination of LOCBE doses for iv administration to rabbits}

The MDIB for $i v$ LOCBE infusion in rabbits was $3.0 \mu \mathrm{g} / \mathrm{kg}$. This dose induced blood incoagulability for at least $7 \mathrm{~h}$, with WBCT returning to normal levels within $24 \mathrm{~h}$.

\section{Evaluation of LOCBE lytic activity on preformed venous thrombus in rabbits}

Thirty minutes after thrombus induction, drugs were infused $i v$ in all animals $(\mathrm{N}=8$, for each treatment group). All saline-treated rabbits showed non-occlusive thrombi with a mean wet and dry weight of $128.87 \pm 16.26$ and $41.62 \pm 5.83 \mathrm{mg}$, respectively. Streptokinase $(30,000 \mathrm{IU} / \mathrm{kg})$ induced total thrombus lysis in 6 of the 8 animals and significantly decreased the mean thrombus weight in the 2 remaining animals $(19 \pm 1.41$ and $7.10 \pm 0.14$, wet and dry weights, respectively). Even at doses that produced total incoagulability and higher plasma fibrinolytic activity, LOCBE did not reduce the frequency or mean weight of venous thrombi present in these animals (groups treated with LOCBE at $1.5,3.0$ and $4.5 \mu \mathrm{g} / \mathrm{kg}$ ). The result obtained with streptokinase was statistically different from control and the three doses of LOCBE (paired $t$-test).

\section{Coagulation and fibrinolysis assays}

Treatment with LOCBE (3.0 and $4.5 \mu \mathrm{g} /$ $\mathrm{kg})(\mathrm{N}=8$ for each treatment group) reduced plasma fibrinogen concentrations to undetectable values and induced total incoagulability. The lowest dose of LOCBE $(1.5 \mu \mathrm{g} /$ $\mathrm{kg}$ ) did not significantly change APTT, TT, or PT when compared to control animals that received saline infusion $(\mathrm{N}=8)$.

Streptokinase $(30,000 \mathrm{IU} / \mathrm{kg})$ increased TT by $73 \%(\mathrm{P}<0.001)$ and PT by $12.7 \%$ in comparison with pre-infusion values. In addition, streptokinase reduced plasma fibrinogen concentration by $30 \%$ (from $276 \pm 43$ to $192 \pm 38 \mathrm{mg} \%, \mathrm{P}<0.001)$.

Increases in lysis areas on fibrin-agarose plates (pre- $v s$ post-infusion values) produced by euglobulin fractions from 8 animals treated with streptokinase were significantly higher than those of LOCBE-treated groups. In the streptokinase-treated group, the mean increase was $77 \%$ (from $153 \pm 7$ to $272 \pm 12 \mathrm{~mm}^{2}$, $\mathrm{P}<0.001$ ), while in the LOCBE-treated groups, increases were of $17 \%$ at $3.0 \mu \mathrm{g} / \mathrm{kg}$ (from 159 \pm 17 to $186 \pm 13 \mathrm{~mm}^{2}, \mathrm{P}=0.004$ ) and $20 \%$ at $4.5 \mu \mathrm{g} / \mathrm{kg}$ (from $172 \pm 15$ to $206 \pm 19 \mathrm{~mm}^{2}, \mathrm{P}$ $=0.002)$ (Table 4).

\section{Discussion}

The present study on the thrombolytic effect of LOCBE was carried out in rabbits,

Table 3. Mean fibrinogen concentration in rat and rabbit plasmas after injection of Lonomia obliqua caterpillar bristle extract (LOCBE).

\begin{tabular}{|c|c|c|c|c|}
\hline \multirow[t]{2}{*}{ Animal } & \multirow[t]{2}{*}{ Pre-infusion value } & \multicolumn{3}{|c|}{ Hours after infusion } \\
\hline & & 0.5 & 2 & 4 \\
\hline \multicolumn{5}{|l|}{ Rats } \\
\hline $5.0 \mu \mathrm{g} / \mathrm{kg}$ & $540.6 \pm 27.8$ & $406.8 \pm 17.4^{*}$ & & $397.7 \pm 57.8^{*}$ \\
\hline $10.0 \mu \mathrm{g} / \mathrm{kg}$ & $552.3 \pm 26.3$ & $0^{*}$ & & $0^{*}$ \\
\hline \multicolumn{5}{|l|}{ Rabbits } \\
\hline $3.0 \mu \mathrm{g} / \mathrm{kg}$ & $263.0 \pm 8.8$ & & $0^{*}$ & \\
\hline
\end{tabular}

Values are reported as $\mathrm{mg} \%$ (means $\pm \mathrm{SD}$ ). $\mathrm{N}=8$ animals in each group. 0 , not found. $* \mathrm{P}<0.05$ compared to control (pre-infusion values; paired t-test). 
since this model of venous thrombosis is highly reproducible and has been used by others with a good thrombolytic response to agents such as streptokinase (31). Non-occlusive thrombi inside the rabbit jugular vein were formed $10 \mathrm{~min}$ after induction and remained in place up to $5 \mathrm{~h}$ in $100 \%$ in the control group animals. Streptokinase induced both thrombolysis and an increase in fibrinolytic activity. LOCBE infusion did not cause thrombolysis at the doses used, but slightly increased fibrinolytic activity. This fibrinolytic activity detected after LOCBE infusion may have been caused by secondary activation of fibrinolysis, not sufficient to cause local thrombolysis.

Induction of thrombosis by venous stasis in the vena cava or by endothelial injury in the jugular vein of rats induced thrombus formation in all control animals. This model of thrombosis induction by vena cava ligature was chosen because it is simple, sensitive and highly reproducible. In addition, one antithrombotic drug of reference (heparin) can be used (32). The other method for venous thrombosis induction by injection of hypertonic glucose was used to study possible LOCBE antithrombotic activity on thrombi formed due to endothelial injury.

In these models, $i v$ infusion of LOCBE at the dose of $10.0 \mu \mathrm{g} / \mathrm{kg}$ completely prevented thrombus formation, inducing blood incoagulability by afibrinogenemia and increasing BT by 2.4 -fold. These alterations were reversed within $24 \mathrm{~h}$. LOCBE at $5.0 \mu \mathrm{g} / \mathrm{kg}$ also prevented thrombus formation in the jugular vein and vena cava in 6 and 7 of the 8 tested animals, respectively. This dose produced a mean $25 \%$ reduction of plasma fibrinogen concentration, preserving normal coagulation assay values, but increasing BT 1.2-fold. At this dose, LOCBE showed antithrombotic activity similar to that obtained with heparin, with fewer alterations in coagulation assays. Also, blood samples collected from LOCBE-treated animals $(5.0 \mu \mathrm{g} /$ kg) 30 min after infusion showed WBLT <2 $\mathrm{h}$, suggesting an activation of the fibrinolytic system or an increased clot susceptibility to plasmin activity. When plasma from these

Table 4. Effects of streptokinase and Lonomia obliqua caterpillar bristle extract (LOCBE) infusion on the coagulation parameters of rabbits.

\begin{tabular}{|c|c|c|c|c|}
\hline \multirow[t]{2}{*}{ Compound } & \multicolumn{4}{|c|}{ Assays } \\
\hline & $\pi$ & PT & APTT & Lysis \\
\hline \multicolumn{5}{|c|}{ SK $(30,000$ IU $/ \mathrm{kg})$} \\
\hline$-15 \min$ & $15.6 \pm 2.0$ & $16.3 \pm 3.2$ & $59.2 \pm 3.2$ & $153.7 \pm 7.8$ \\
\hline$+180 \min$ & $25.6 \pm 2.8^{*}$ & $18.7 \pm 2.3$ & $56.5 \pm 4.8$ & $272.3 \pm 12.5^{*}$ \\
\hline \multicolumn{5}{|c|}{ LOCBE $(1.5 \mu \mathrm{g} / \mathrm{kg})$} \\
\hline$-15 \min$ & $14.1 \pm 2.6$ & $15.0 \pm 2.0$ & $56.2 \pm 5.7$ & $167.8 \pm 20.2$ \\
\hline$+180 \min$ & $14.8 \pm 2.0$ & $14.7 \pm 3.2$ & $56.6 \pm 5.7$ & $169.3 \pm 39.7$ \\
\hline \multicolumn{5}{|c|}{ 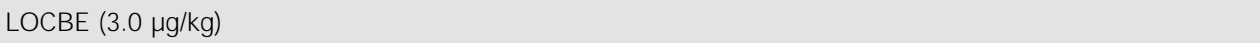 } \\
\hline$-15 \mathrm{~min}$ & $14.7 \pm 2.2$ & $14.8 \pm 3.1$ & $55.7 \pm 6.3$ & $159.2 \pm 17.3$ \\
\hline+180 min & Inc* & Inc* & Inc* & $186.0 \pm 13.0$ \\
\hline \multicolumn{5}{|c|}{ LOCBE $(4.5 \mu \mathrm{g} / \mathrm{kg})$} \\
\hline$-15 \mathrm{~min}$ & $14.2 \pm 2.1$ & $12.8 \pm 2.4$ & $56.2 \pm 5.4$ & $172.5 \pm 15.5$ \\
\hline$+180 \mathrm{~min}$ & Inc* & Inc* & Inc* & $206.7 \pm 19.7^{*}$ \\
\hline \multicolumn{5}{|c|}{$\begin{array}{l}\text { The animals received streptokinase }(\mathrm{SK}, 30,000 \mathrm{IU} / \mathrm{kg} \text { ) or } \mathrm{LOCBE} \text { at the doses of } 1.5,3.0 \text { and } 4.5 \mu \mathrm{gg} / \mathrm{kg} \text {. Blood } \\
\text { samples were collected } 15 \mathrm{~min} \text { before }(-15) \text { and } 180 \mathrm{~min} \text { after drug infusion. Values are reported as seconds } \\
\text { (mean } \pm \mathrm{SD}) . \mathrm{N}=8 \text { animals in each group. } \Pi \text {, thrombin time; PT, prothrombin time; APTT, activated partial } \\
\left.\text { thromboplastin time; Lysis area ( } \mathrm{mm}^{2}\right) \text {; Inc, incoagulable. } \\
* \mathrm{P}<0.05 \text { for each treatment aroup compared to control (paired t-test). }\end{array}$} \\
\hline
\end{tabular}


blood samples was incubated with sodium iodoacetate and then recalcified, the resulting clots were dissolved within less than 90 $\min$ (control $>24 \mathrm{~h}$ ) after re-suspension in $5 \mathrm{M}$ urea, suggesting a low concentration or low activity of factor XIII. The decrease in factor XIII level or activity reduces crosslinking of $\alpha_{2}$-antiplasmin to fibrin, amplifying the action of plasmin (33).

Despite some difficulty in interpreting the effects of crude extracts on hemostasis, at least part of the anticoagulant and antithrombotic effects observed in our experiments is probably a consequence of fibrinogen consumption, as reported for a number of substances isolated from snake venoms, such as ancrod, batroxobin and crotalase. However, the mechanism of action of these snake enzymes seems to be different, as they provoke a direct cleavage of fibrinopeptide A from fibrinogen, without activation or consumption of factor XIII $(34,35)$. Although it has been shown that LOCBE activates factor $X$ (14) and a fraction that activates prothrombin has been isolated and characterized in vivo $(16,36)$, the intrinsic mechanism of the hypofibrinogenemia induced by LOCBE is not completely understood and needs further investigation.

The decreased level of plasma factor XIII zymogen in treated animals in our experiments seems to be similar to that observed in human accidents with Lonomia caterpillars
(37). However, this decrease in plasma factor XIII in plasma of envenomed patients, after contact with L. achelous and L. obliqua caterpillars seems to be a consequence of different mechanisms. The venom of $L$. achelous contains one well-characterized substance that degrades human factor XIII in vitro (10-12,37). This substance, called Lonomin $\mathrm{V}$, produces a dose-dependent thrombolysis in combination with a decrease in factor XIII level (37). To date, however, no similar substance was described in $L$. obliqua venom. The differences in the in vitro activity of L. obliqua and L. aquelous toxins could be due to species differences or different caterpillar materials. Tests with $L$. aquelous have been mainly performed with hemolymph, while tests with L. obliqua were performed with bristle extracts (37). One possible explanation for the low level of factor XIII in the treated rats in our experiments could be consumption, as observed in other types of disseminated intravascular coagulation (38).

The mechanism of action of the significant increase of BT seen in LOCBE-treated rats is unexplained, and deserves further study. The explanation could be alterations in platelet number or function or in vascular reactivity and the increase in BT could be induced by the antithrombotic components or by other substances present in this crude extract.

\section{References}

1. Arocha-Piñango $C L$, Marchi $R$, Canvajal $Z$ \& Guerrero B (1999). Invertebrate compounds acting on the hemostatic mechanism. Blood Coagulation and Fibrinolysis, 10: 43-68.

2. Markwardt F (1989). Development of hirudin as an antithrombotic agent. Seminars in Thrombosis and Hemostasis, 15: 269282.

3. Vlasuk GP, Ramjit D, Fujita T, Dunwiddie $C T$, Nutt EM, Smith DE \& Shebiski RJ (1991). Comparison of the in vivo anticoagulant properties of standard heparin and the highly selective factor $\mathrm{Xa}$ inhibitors antistasin and tick anticoagulant peptide (TAP) in a rabbit model of venous thrombosis. Thrombosis and Haemostasis, 65: 257-262.

4. Arocha-Piñango CL (1967). Fibrinólysis producida por contato con orugas. Comunicación preliminar. Acta Cientifica Venezolana, 18: 136-139.

5. Arocha-Piñango $\mathrm{CL}$, Bosch NB, Torres $A$, Goldstein C, Nouel A, Arguello A, Carvajal Z, Guerrero B, Ojeda A, Rodrigues A \& Rodrigues S (1992). Six new cases of cat- erpillar-induced bleeding syndrome. Thrombosis and Haemostasis, 67: 402407.

6. Arocha-Piñango CL \& Layrisse M (1969). Fibrinolysis produced by contact with a caterpillar. Lancet, 1: 810-812.

7. Arocha-Piñango $\mathrm{CL}$, Blumenfeld-Bosch $\mathrm{N}$, Nouel AL, Torres A, Perales J, Alonso ME, Rodriguez S, Carvajal AZA, Ojeda A, Tasayco ML \& Chitty W (1988). FibrinoIytic and procoagulant agents from a Satumiidae moth caterpillar. In: Pirkle $\mathrm{H} \&$ Markland FS (Editors), Haemostasis and 
Animal Venoms. Marcel Dekker, Inc., New York, NY, USA.

8. Guerrero B \& Arocha-Piñango CL (1992). Activation of human prothrombin by the venom of Lonomia achelous (Cramer) caterpillars. Thrombosis Research, 66: 169-177.

9. Amarant $\mathrm{T}$, Burkhart $\mathrm{W}$, Le Vine $\mathrm{H}$, Arocha-Piñango CL \& Parick I (1991). Isolation and complete amino acid sequence of two fibrinolytic proteinases from the toxic saturnid caterpillar Lonomia achelous. Biochimica et Biophysica Acta, 1079: 214-221.

10. Guerrero BAG, Arocha-Piñango $C L \& J$ uan AGS (1997). Degradation of human factor XIII by Lonomin V, a purified fraction of Lonomia achelous caterpillar venom. Thrombosis Research, 87: 171-181.

11. Guerrero BAG, Arocha-Piñango CL \& J uan AGS (1997). Lonomia achelous caterpillar venom (LACV) selectively inactivates blood clotting factor XIII. Thrombosis Research, c87: 83-93.

12. Guerrero BAG, Perales J, Gil A \& ArochaPiñango $C L$ (1999). Effect on platelet FXIII and partial characterization of Lonomin V, a proteolytic enzyme from Lonomia achelous caterpillars. Thrombosis Research, 93: 243-252.

13. Kelen EMA, Picarelli ZP \& Duarte AC (1995). Hemorrhagic syndrome induced by contact with caterpillars of the genus Lonomia (Saturniidae, Hemileucinae). J oumal of Toxicology. Toxin Reviews, 14: 283-308.

14. Donato J L, Moreno RA, Hyslop S, Duarte A, Antunes E, Le Bonniec BF, Rendu F \& de Nucci G (1998). L. obliqua caterpillar spicules trigger human blood coagulation via activation of factor $X$ and prothrombin. Thrombosis and Haemostasis, 79: 539542.

15. Silva WD, Campos ACMR, Gonçalves LRC, Sousa e Silva MCC, Higashi HG, Yamagushi I \& Kelen EMA (1996). Development of an antivenom against toxins of L. obliqua caterpillars. Toxicon, 34: 10451049.

16. Reis CV, Kelen EMA, Farsky SHP, Portaro FCV, Sampaio CAM, Fernandes BL, Camargo ACM \& Chudzinski-Tavassi AM (1999). A Ca ${ }^{2+}$ activated serine protease (LOPAP) could be responsible for the haemorrhagic syndrome caused by the caterpillar L. obliqua. Lancet, 353: 1942.

17. Giles AR (1987). Guidelines for the use of animals in biochemical research. Thrombosis and Haemostasis, 58: 1078-1084.

18. Markwell MAK, Haas SM, Bieber LL \& Tolbert NE (1978). A modification of the Lowry procedure to simplify protein determination in membrane and lipoprotein samples. Analytical Biochemistry, 87: 206210.

19. Denson KWE (1972). Appendix 2: techniques. In: Biggs R (Editor), Human Blood Coagulation Haemostasis and Thrombosis. Blackwell Scientific Publications, Oxford, England.

20. Reyers I, Mussoni L, Donati BL \& Gaetano G (1980). Failure of aspirin at different doses to modify experimental thrombosis in rats. Thrombosis Research, 18: 669674.

21. Maffei FHA, Rollo HA \& Fabris VE (1980). Prevention of experimental venous thrombosis induced by contrast medium in the rat. Acta Radiologica Diagnosis, 21: 249252.

22. Seegers WH \& Smith HP (1942). Factors which influence the activity of purified thrombin. American J oumal of Physiology, 137: 348-354.

23. Ratnoff OD \& Menzie ABC (1951). A new method for the determination of fibrinogen in small samples of plasma. J ournal of Laboratory and Clinical Medicine, 37: 316-320.

24. Dejana E, Callioni A \& Quintana A (1979). Bleeding time in laboratory animals. II - A comparison of different assay conditions in rats. Thrombosis Research, 15: 191197.

25. Sigg $P$ (1966). The monoiodoacetate (MIA) tolerance test, a new quantitative method for the fibrin stabilizing factor (Factor XIII) assay. Thrombosis et Diathesis Haemorrhagica, 15: 238-251.

26. Rollo HA, Maffei FHA, Yoshida WB, Lastória S, Curi PR \& Mattar L (1991). Heparin, heparin plus ASA and dipyridamole, and arteriovenous fistula as adjuvant methods to prevent rethrombosis after venous thrombectomy. International Angiology, 10: 88-94.

27. Porter NR (1983). Euglobulin clot lysis time. European Concerted Action of Thrombosis and Disabilities. Assay Procedures, ECAT Manual (No. 2).

28. Kluft C, Brakman $P \&$ Veldhuyzen-Stolk EC (1976). Screening of fibrinolytic activity in plasma euglobulin fractions on the fibrin plate. In: Davidson J F, Samama MM
\& Desnoyers PC (Editors), Progress in Chemical Fibrinolysis and Thrombolysis. Vol. 2. Raven Press, New York, NY, USA.

29. Granelli-Piperno A \& Reich E (1978). A study of proteases and protease-inhibitor complexes in biological fluids. J oumal of Experimental Medicine, 148: 223-234.

30. Curi PR (Editor) (1998). Metodologia e Análise da Pesquisa em Ciências Biológicas. Tipomic, Botucatu, SP, Brazil.

31. Nowak A \& Gurewich V (1974). Thrombolysis with streptokinase in rabbits-dose response, fibrin-clot specificity and laboratory evaluation of fibrinolytic effect. Thrombosis et Diathesis Haemorrhagica, 31: 265-272.

32. Andriuoli G, Mastacchi R, Barbanti $M$ \& Sarret M (1985). Comparison of the antithrombotic and haemorrhagic effects of heparin and a new low molecular weight heparin in rats. Haemostasis, 15: 324-330.

33. Sakata Y \& Aoki N (1982). Significance of cross-linking of $\alpha_{2}$-plasmin inhibitor to fibrin in the inhibition of fibrinolysis and in hemostasis. J ournal of Clinical Investigation, 69: 536-542.

34. Markland FS \& Pirkle H (1977). Biological activities and biochemical properties of thrombin-like enzymes from snake venoms. In: Lundblad RL, Fenton J W \& Mann KG (Editors), Chemistry and Biology of Thrombin. Ann Arbor Science Publishers Inc., Ann Arbor, MI, USA.

35. Barlow GH, Holleman WH \& Lorand L (1970). The action of anvin on fibrin stabilizing factor (Factor XIII). Research Communications in Chemical Pathology and Pharmacology, 1: 39-42.

36. Reis CV, Farsky SH, Femandes BL, Santoro $M L$, Oliva $M L, M$ ariano $M \&$ Chudzinski-Tavassi AM (2001). In vivo characterization of lopap, a prothrombin activator serine protease from the Lonomia obliqua caterpillar venom. Thrombosis Research, 102: 437-443.

37. Arocha-Piñango $\mathrm{CL}$, Marval $\mathrm{E} \&$ Guerrero BAG (2000). Lonomia genus caterpillar toxins: Biochemical aspects. Biochimie, 82: 937-942.

38. McDonagh J (1994). Structure and function of Factor XIII. In: Colman RW, Hirsh J, Marder VJ \& Salzman EW (Editors), Hemostasis and Thrombosis. Basic Principles and Clinical Practice. 3rd edn. J.B. Lippincott Company, Philadelphia, PA, USA. 